\title{
A photocatalytic regioselective hydroaminoalkylation of aryl-substi- tuted alkenes with simple amines
}

\author{
Natalia A. Larionova, ${ }^{\mathrm{a}}$ Jun Miyatake Ondozabal, ${ }^{\mathrm{a}}$ Emily G. Smith, ${ }^{\mathrm{a}}$ Xacobe C. Cambeiro ${ }^{\mathrm{b}, *}$ \\ ${ }^{a}$ Department of Chemistry, School of Biological and Chemical Sciences, Queen Mary University of London. Mile End \\ Road, London, E1 4NS United Kingdom \\ ${ }^{\mathrm{b}}$ School of Science, University of Greenwich. Chatham Maritime, ME4 4TB United Kingdom \\ x.cambeiro@gre.ac.uk
}

KEYWORDS Visible light, photoredox, photocatalysis, $\alpha$-aminoalkyl radical, electron-deficient alkene, $\beta$-amino acid, styrene, DFT, continuous flow, anti-Markovnikov, anti-Giese.

\begin{abstract}
A photocatalytic method for the $\alpha$-selective hydroaminoalkylation of cinnamate esters has been developed. The reaction involves the regioselective addition of $\alpha$-aminoalkyl radicals generated from aniline derivatives or aliphatic amines to the $\alpha$ position of unsaturated esters. The scope of aromatic alkenes was extended to styrenes undergoing hydroaminoalkylation with antiMarkovnikov selectivity, which confirms the importance of the aromatic group at the $\beta$-position. Simple scale-up is demonstrated under continuous flow conditions, highlighting the practicality of the method.
\end{abstract}

The addition of carbon-centred radicals to alkenes, besides its importance in polymer chemistry, ${ }^{1}$ is also a powerful method for the formation of C-C bonds in small molecule synthesis. ${ }^{2}$ In particular, radical conjugate addition reactions, commonly known as Giese reaction, ${ }^{3}$ have received much attention. $\alpha$ Aminoalkyl radicals, ${ }^{4}$ consistently with the nucleophilic character imparted on them by the influence of the $\mathrm{N}$ lone pair, engage readily in Giese-type reactions. ${ }^{4 a}, 5$ Exploiting this reactivity, photocatalytic hydroaminoalkylation reactions of electronpoor alkenes have been described throughout the last decade. $^{4 b, c, 6,7}$ A variety of common photocatalysts are readily quenched reductively by tertiary amines giving place, after deprotonation, to $\alpha$-aminoalkyl radicals, which go on to react with Michael acceptors such as maleimides, ${ }^{8}$ alkylidene malonates and malononitriles, ${ }^{9} \alpha, \beta$-unsaturated carbonyl compounds, ${ }^{10}$ amides $^{11}$ and esters, ${ }^{12}$ as well as alkenylpyridine derivatives, ${ }^{13}$ providing straightforward access to densely functionalised structures. In addition, photocatalytic Giese-type reactions ${ }^{14}$ have been described with $\alpha$-aminoalkyl radicals generated by different methods, such as oxidative desilylation ${ }^{15}$ or decarboxylation, ${ }^{16}$ among others. ${ }^{17}$

These transformations proceed generally with high regioselectivity for the $\beta$-position respect of the electron-withdrawing group (Figure 1a), consistent with an early transition state governed by the SOMO-LUMO orbital interaction. As a remarkable exception, Sparling observed $\alpha$-selectivity in a photocatalytic decarboxylative radical addition to $\beta$-aryl $\alpha, \beta$-unsaturated amides (Figure 1b). ${ }^{18}$ The unusual selectivity in this case was attributed to a reversible radical addition, giving place under thermodynamic control to the more stable benzylic radical. However, this method was limited to decarboxylative generation of the $\alpha$-aminoalkyl radical from $\alpha$-amino acid substrates, which required a strongly oxidising catalyst for decarboxylation. ${ }^{19}$
Despite of these difficulties, a method for the direct aminoalkylation of $\alpha, \beta$-unsaturated carboxylic acid derivatives would provide a practical, straightforward route for the preparation of $\beta$-amino acids, important pharmaceutical building blocks. ${ }^{20}$ Moreover, this strategy may enable access to substitution patterns $\left(\beta^{2}\right.$ and $\left.\beta^{2,3}\right)$ which are not easily accessible through more established routes. ${ }^{21}$ Alternative photocatalytic methods for the preparation of $\beta$-amino carbonyl compounds from amines have been reported, based on Mannich-type reactions of photocatalytically generated iminium ions with silyl enol ethers ${ }^{22}$ or with enamines generated in situ using enamine catalysis (Figure 1b) ${ }^{23}$ However, these methods are limited to tetrahydroisoquinoline derivatives as the amine partner. A similar strategy for $\alpha$ olefination of amines is similarly restricted to tetrahydroisoquinoline and tetrahydro- $\beta$-carbolines. ${ }^{24}$

In contrast with the well-established Giese-type addition to electron-poor alkenes, efficient photocatalytic hydroaminoalkylation of less polarised alkenes has not been reported to date. ${ }^{25}$ This is possibly a consequence of poor chemoselectivity in the absence of a good matching or the nucleophilic radical with an electrophilic alkene, giving place to polymerisation side-reactions. ${ }^{26}$

During our recent investigation on photocatalytic transfer hydrogenation of cinnamate derivatives we found a kinetic preference for attack at the $\alpha$-position in a $\mathrm{H}$ atom transfer from Hantzsch ester radical cation to the alkene. ${ }^{27}$ Here we report a photocatalytic method for the $\alpha$-selective hydroaminoalkylation of cinnamate esters based on the regioselective addition of $\alpha$ aminoalkyl radicals, where the reaction is controlled by the presence of an aromatic group at the $\beta$-position. Moreover, our method is valid for the direct hydroaminoalkylation of styrenes, which proceeds with high anti-Markovnikov selectivity (Figure 1c). 
Figure 1. Summary of hydroaminoalkylation of electron-poor alkenes and related transformations.
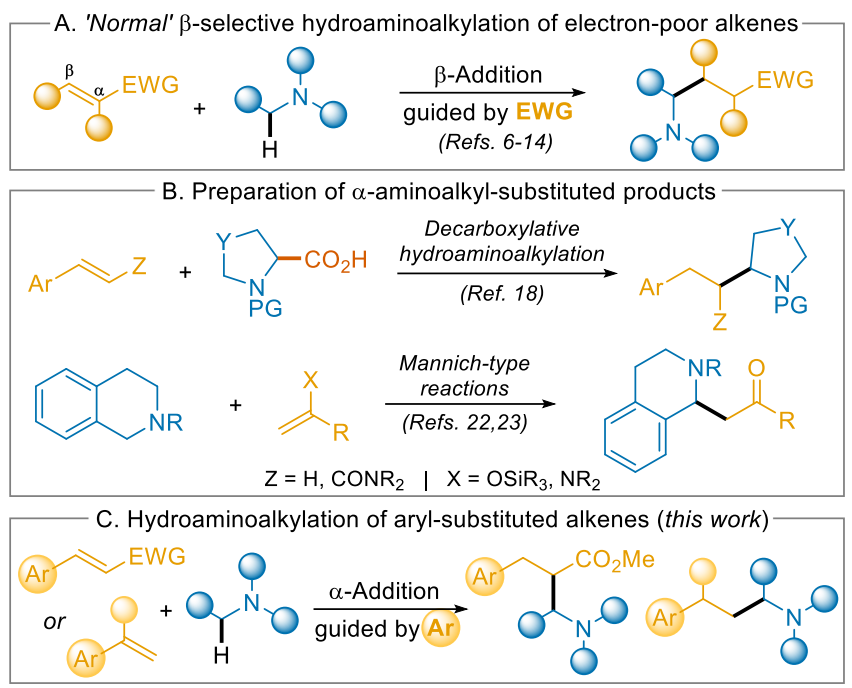

Irradiation with blue light of a MeCN solution of cinnamate ester 1a and dimethylaniline $2 \mathbf{a}$ (1.5 equiv) in the presence of photocatalyst $\left[\operatorname{Ir}(\mathrm{ppy})_{2}(\mathrm{dtbbpy})\right] \mathrm{PF}_{6}(1 \mathrm{~mol} \%)$ and $\mathrm{Cs}_{2} \mathrm{CO}_{3}(20$ mol\%) resulted in quantitative formation of $\beta$-amino ester $3 \mathbf{a a}$ and its $\gamma$-isomer in 3:1 ratio (Scheme 1), resulting in a preference for $\alpha$-addition of the aminoalkyl radical. The use of the organic, soluble base DBU provided results comparable to $\mathrm{Cs}_{2} \mathrm{CO}_{3}$, as did the use of increased loadings of base. Other modifications to the reaction conditions resulted generally in decreased yields. ${ }^{28}$

To determine the scope of the reaction we first applied it to a range of cinnamate derivatives (Scheme 1). The presence of

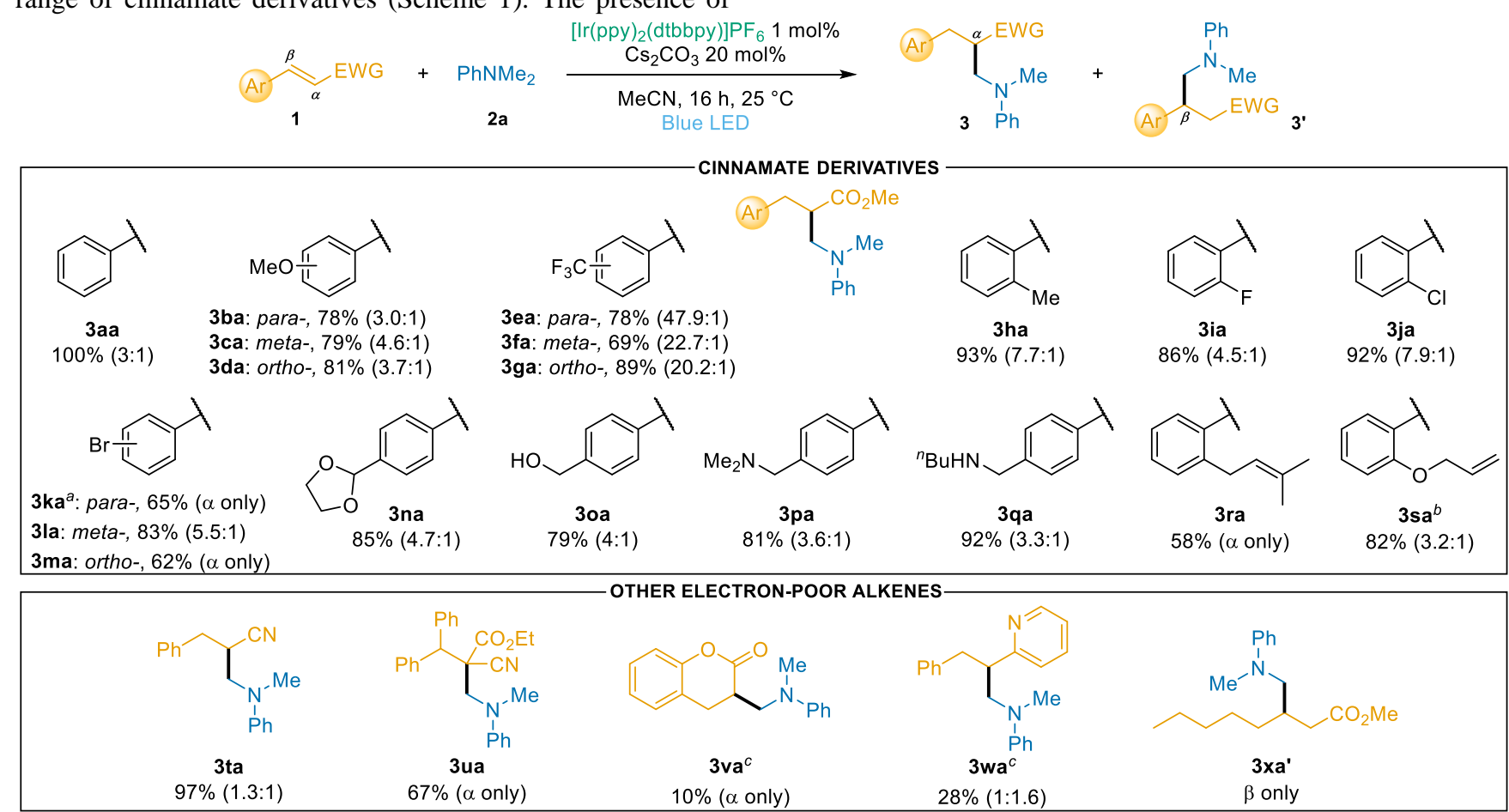

electron-donating $\mathrm{MeO}$ substituent on either position of the aryl ring was well tolerated, resulting in products 3 ba-da with yields ranging from 78 to $81 \%$ and regioselectivities between 3:1 and 4.6:1. Similarly, electron-withdrawing group $\mathrm{CF}_{3}$ provided products 3ea-ga in 69 to $81 \%$ yield and significantly increased $20: 1$ to $48: 1$ regioselectivity, always favouring the product of $\alpha$ addition. In both cases the position of substitution had no apparent effect on the reaction, suggesting that steric hindrance was not very relevant. Consistently, ortho-Me substituted product 3ha was also readily formed (93\% yield, 7.7:1). Halogens were tolerated as well and led to increased regioselectivities compared to 3aa (between 62 and 92\% yield and 4.5:1 to quantitative regioselectivity for products $\mathbf{3 i a}$ through $\mathbf{3 m a}$ ). These halogen substituents provide useful handles for further functionalisation of the products through metal-catalysed cross-couplings or photocatalytic transformations. Acetal-protected aldehyde 3na could be obtained in $85 \%$ yield and $4.7: 1$ selectivity, offering further diversity of functionalities. Similarly, the reaction was compatible with the presence of benzylic alcohol, tertiary and even secondary amine (respectively: 3oa, 79\%, 4:1; 3pa, 81\%, 3.6:1; 3qa, 92\%, 3.3:1). Finally, the reaction worked in the presence of a dimethylallyl or an allyloxy substituents, leading to formation of products 3ra $(58 \%, \alpha$ only) and 3sa $(82 \%, 3.2: 1$, starting from the $Z$-alkene) with no detectable reaction on the allyl groups. This suggests that the radical formed after addition rapidly reacts further to provide compound $3{ }^{29}$

Cinnamonitrile was also a valid substrate for the reaction, although the corresponding product 3 ta was obtained with a very poor regioselectivity against its $\beta$-addition analogue (1.6:1). Product 3ua, conversely, was obtained with complete regioselectivity in $67 \%$ yield from the corresponding tetrasubstituted

Scheme 1. Hydroaminomethylation of electron-poor alkenes (1) with $N, N$-dimethylaniline (2a). Reactions carried out with 1 (0.2 mmol), 2a (1.5 equiv), [ $\left.\operatorname{Ir}(\mathrm{ppy})_{2}(\mathrm{dtbbpy})\right] \mathrm{PF}_{6}(1 \mathrm{~mol} \%)$ and $\mathrm{Cs}_{2} \mathrm{CO}_{3}(20 \mathrm{~mol} \%)$ in $\mathrm{MeCN}(2 \mathrm{~mL})$, under blue light irradiation for 16 $\mathrm{h}$ while controlling the temperature at $25^{\circ} \mathrm{C}$. Yields are of isolated product unless otherwise noted. Numbers in brackets are $\alpha$ to $\beta$ ratio determined by ${ }^{1} \mathrm{H}$ NMR. ${ }^{a}$ The ethyl ester was used in this case instead of methyl. ${ }^{b}$ Starting material was the $Z$-alkene. ${ }^{c}$ Yield determined by ${ }^{1} \mathrm{H}$ NMR using an internal standard. 


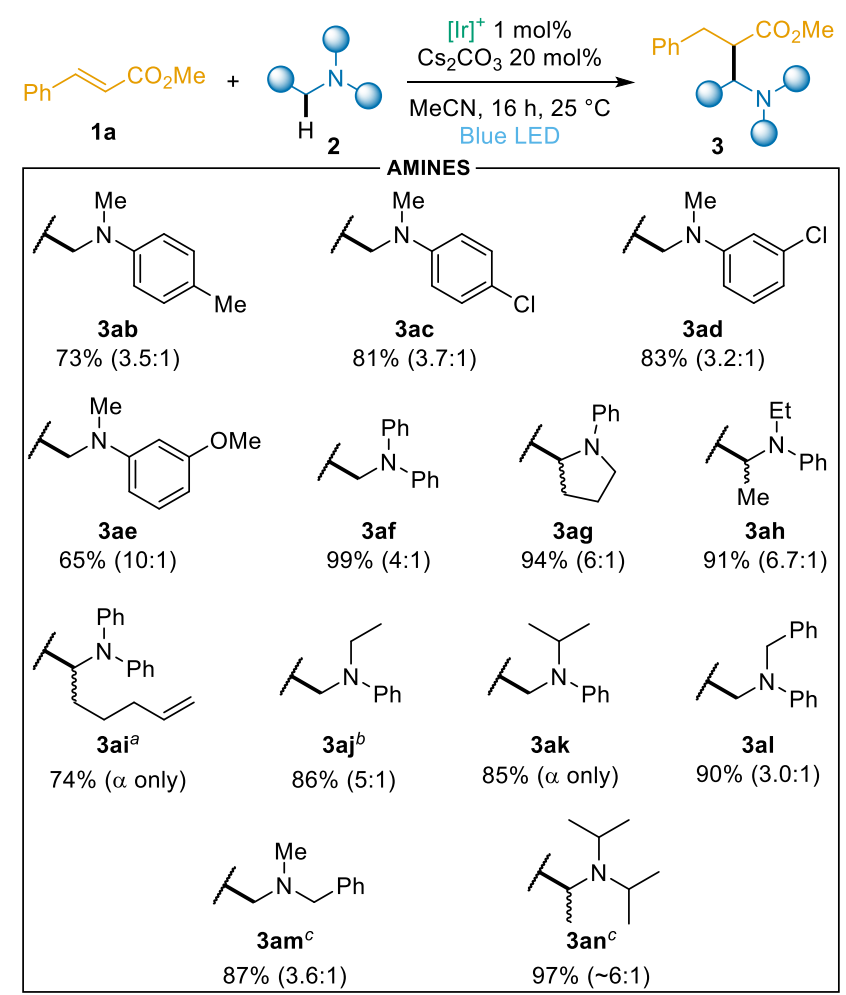

Scheme 2. Hydroaminomethylation of methyl cinnamate (1a) with amines (2). Reaction conditions as in Scheme 1. $[\mathrm{Ir}]^{+}=\left[\operatorname{Ir}(\mathrm{ppy})_{2}(\mathrm{dtbbpy}) \mathrm{PF}_{6} \cdot{ }^{a} 0.2 \mathrm{mmol}\right.$ of 2 and 3 equiv. of $\mathbf{1 a}$ were used. ${ }^{b}$ Product was obtained as a 7:1 mixture of regioisomers. ${ }^{c}$ Characterised as mixture of $\alpha / \beta$.

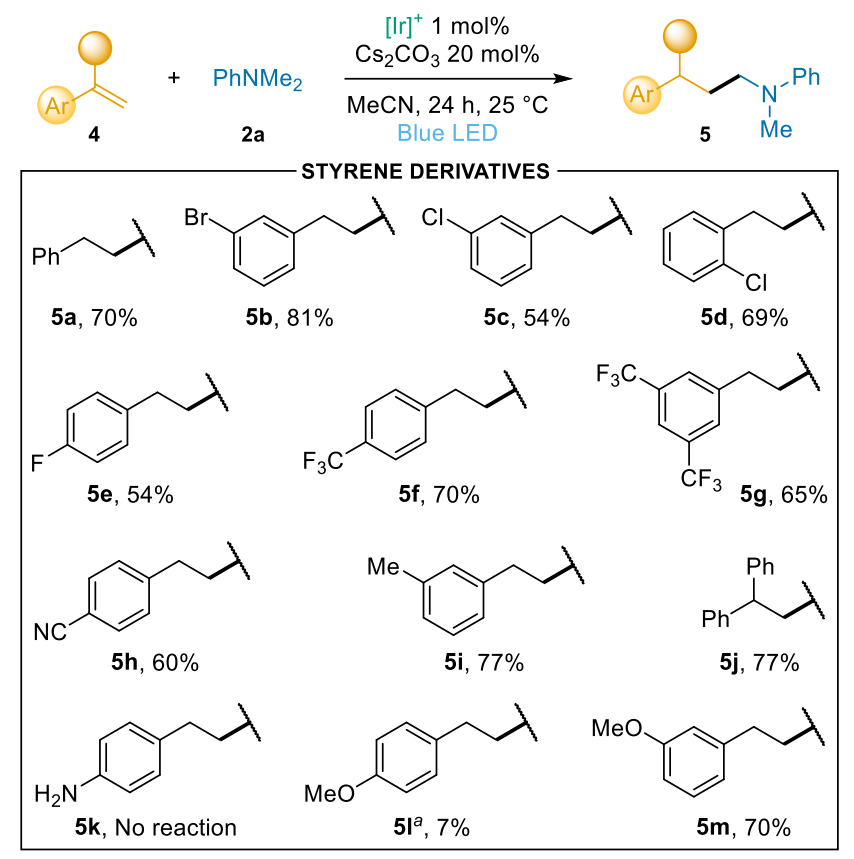

Scheme 3. Hydroaminomethylation of styrene derivatives (4) with $N, N$-dimethylaniline (2a). Reactions carried out with $\mathbf{4}$ (0.2 mmol), $2 \mathbf{a}\left(2\right.$ equiv), $\left[\operatorname{Ir}(\mathrm{ppy})_{2}(\mathrm{dtbbpy})\right] \mathrm{PF}_{6}(1 \mathrm{~mol} \%)$ and $\mathrm{Cs}_{2} \mathrm{CO}_{3}(20 \mathrm{~mol} \%)$ in $\mathrm{MeCN}(8 \mathrm{~mL})$, under blue light irradiation for $24 \mathrm{~h}$ while controlling the temperature at $25^{\circ} \mathrm{C}$. Yields are of isolated product. $[\operatorname{Ir}]^{+}=\left[\operatorname{Ir}(\text { ppy })_{2}(\mathrm{dtbbpy})\right] \mathrm{PF}_{6} \cdot{ }^{a}$ Yield determined by ${ }^{1} \mathrm{H}$ NMR using an internal standard. alkene. A cyclic $\alpha, \beta$-unsaturated ester, coumarin, was transformed to 3va regioselectively but in very low yield (12\%), and 2-styrylpyridine gave 3wa in low yield and selectivity, with a slight preference for the $\beta$-addition product $(28 \%, 1: 1.6)$. Finally, an $\alpha, \beta$-unsaturated ester bearing only an aliphatic substituent reacted to give exclusively the $\beta$-addition product 3xa'.

Then, we explored the reactivity of different amines (Scheme 2 ). The reaction proceeds well with substituted dimethylaniline derivatives (3ab to 3ae) as well as with methyldiphenylamine (3af). $N$-phenylpyrrolidine and $N, N$-diethylaniline provided products 3ag and 3ah in excellent yields and regioselectivities (respectively: 94\%, 6:1 and 91\%, 6.7:1), although with no diastereoselectivity. Similar to above mentioned observations for products 3qa and 3ra, an alkene-substituted diphenylamine derivative resulted in formation of product 3ai (74\%, exclusive $\alpha$ ) with no cyclisation of the pendant terminal alkene. Non-symmetrically substituted anilines tended to react at the position leading to the least stable radical. Thus, $N$-ethyl- $N$-methylaniline gave 3aj (86\%, 5:1 $\alpha: \beta$ ratio) as the major product, while $N$-methyl- $N$-isopropylaniline and $N$-methyl- $N$-benzylaniline gave 3ak $(85 \%, \alpha$ only) and 3al $(90 \%, 3: 1 \alpha: \beta$ ratio), with no reaction observed at the isopropyl and benzyl substituents, respectively. Remarkably, the reaction was not limited to aniline derivatives: products 3am and 3an were readily obtained from their parent amines in good yields and selectivities (respectively: $87 \%, 3.6: 1 ; 97 \%, \sim 6: 1)$.

Finally, we explored the reactivity under our conditions of styrene derivatives, not bearing the electron-withdrawing group on the alkene (Scheme 3 ). Both styrene and a range of derivatives reacted smoothly with $\mathrm{N}, \mathrm{N}$-dimethylaniline to give the corresponding hydroaminomethylation products $\mathbf{5 a - i}$ in good yields (54 to $81 \%$ ) and with complete anti-Markovnikov regioselectivity. ${ }^{30}$ Similarly, 1,1-diphenylethene provided product $\mathbf{5 j}$ in $77 \%$ yield. It is worth noting that, while these examples show that an electron-withdrawing group directly bound to the alkene was not necessary, high electron density was still detrimental to the reaction: Thus, $p$-aminostyrene did not react and $p$-methoxystyrene provided only low yields of the product $(\mathbf{5 k}$, 5l). A $m$-methoxy substituent, having an overall electron-withdrawing effect (Hammet $\sigma_{\mathrm{m}}=+0.115 v s$. $\sigma_{\mathrm{p}}=-0.268$ ), provided $\mathbf{5 m}$ in $70 \%$ yield.

The simple conditions employed allowed for the straightforward translation into a readily scalable continuous flow method. Thus, a MeCN solution of alkene, amine and catalyst containing $20 \mathrm{~mol} \%$ of DBU was pumped through a coil of PTFE tube which was illuminated with blue LEDs. The collected solution, after workup and purification, afforded the corresponding $\beta$ amino ester product. This method was applied, with excellent

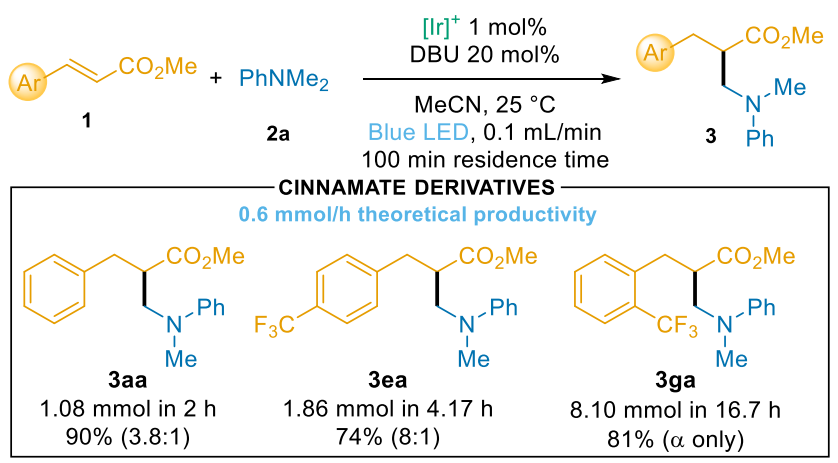

Scheme 4. Continuous-flow production of $\beta$-amino esters. 
Figure 2. Plausible mechanism for the hydroaminoalkylation.

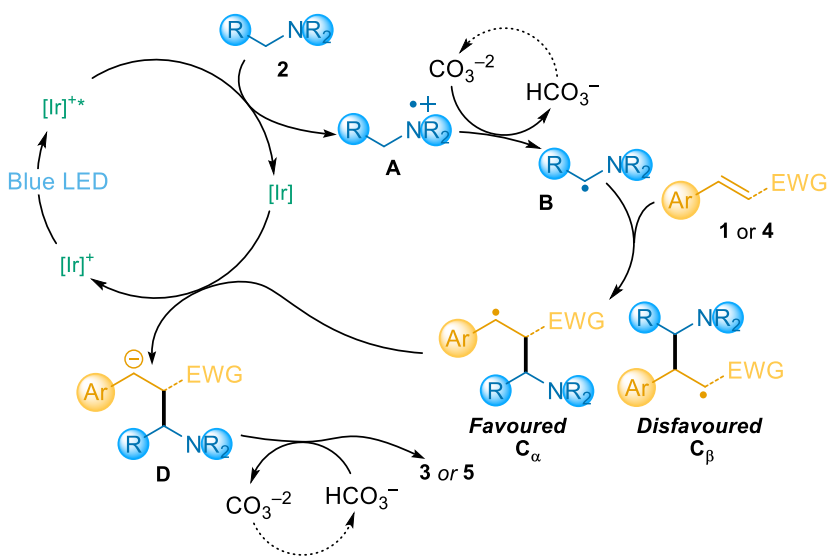

results, to the preparation of compounds 3aa, 3ae and 3ag (Scheme 4).

A plausible mechanism for the reaction (Figure 2) would involve reductive quenching of the excited catalyst $\left(\mathrm{E}^{\circ} \mathrm{Ir} /{ }^{*} \mathrm{Ir}^{+}=\right.$ $0.66 \mathrm{~V})$ by amine $2\left(\mathrm{E}^{\circ} \mathbf{2}^{+} / \mathbf{2}=0.71 \mathrm{~V}\right)$ followed by deprotonation to form and aminoalkyl radical $\mathbf{B},{ }^{31,32}$ which would then add across the alkene substrate ( $\mathbf{1}$ or $\mathbf{4}$ ) double bond. Reduction of the resulting benzylic radical $\mathbf{C}_{\boldsymbol{\alpha}}$ followed by protonation would lead to product $\mathbf{3}$ or $\mathbf{5}$. To probe this mechanism, we irradiated $N, N$-dimethylaniline $\mathbf{2 a}$ under our standard reaction conditions in the absence of alkene, upon which we detected the formation of ethylenediamine 6 (Scheme 5a). The same reaction in the presence of nitromethane did not result in any observable formation of the nitromethane adduct 7 (Scheme 5b), which would be expected if oxidation of the amine to iminium occurred in any significant amount. ${ }^{33}$ Conversely, analogous experiments in the absence of $\mathrm{Cs}_{2} \mathrm{CO}_{3}$ resulted, respectively, in no observable formation of $\mathbf{6}$ and detection of $\mathbf{7}$ with nitromethane.

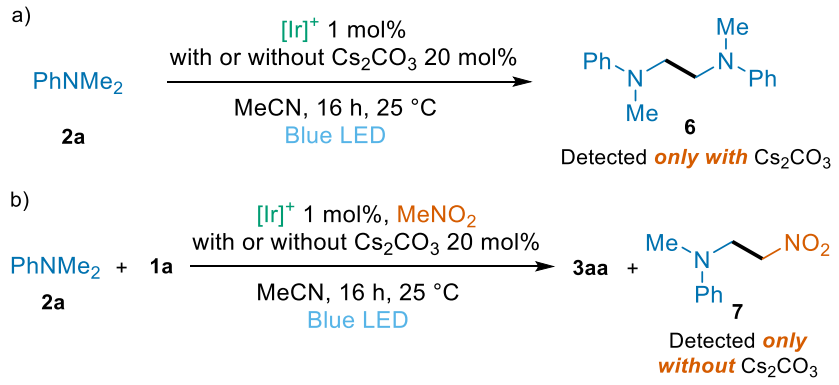

Scheme 5. Experiments for detection of aminoalkyl radical or iminium.

DFT calculations (PBE0-GD3/6-31+G(d,p), SMD model for $\mathrm{MeCN}$, Figure 3) were also consistent with our mechanistic hypothesis: Transition states for the radical addition at positions $\alpha$ and $\beta$ were both energetically accessible, with addition at $\alpha$ favoured by $1.0 \mathrm{kcal} / \mathrm{mol}$, a small but significant difference consistent with the observed regioselectivity. Furthermore, the radical addition step was exergonic by -10.2 and $-5.2 \mathrm{kcal} / \mathrm{mol}$, respectively, for the $\alpha$ and $\beta$ additions, and the calculated reduction potentials of the resulting benzylic or enol radical $(-1.47$ and $-0.94 \mathrm{~V}$ ) indicate an easy reduction to the corresponding anions by the reduced form of the catalyst $\left(\mathrm{E}^{0}=-1.51 \mathrm{~V}\right.$ vs. SCE). ${ }^{32 a}$ These observations, combined with the absence of cyclisation products in the reactions leading to compounds 3ra, 3sa and 3ai, provide support for a kinetic control of regioselectivity rather than a reversible radical addition under thermodynamic control.

In conclusion, the methodology presented allows the hydroaminoalkylation of a wide variety of moderately electronpoor alkenes, including styrene derivatives, with aniline derivatives as well as aliphatic amines. Besides, the method is readily scalable under continuous flow conditions. Computational data suggest that the reaction is driven by the presence of the aromatic substituent, which controls reactivity and regioselectivity. An accurate balance between the aromatic substituent and the electron-withdrawing group are necessary for selectivity, with stronger EWGs leading to Giese-type addition, which will be of importance for the development of related regioselective methodologies further expanding the scope of these transformations.

Figure 3. DFT-calculated energy profile for the radical addition [PBE0-GD3/6-31+G(d,p), energies reported are Gibbs free energy in solution (SMD model for $\mathrm{MeCN}$ )].
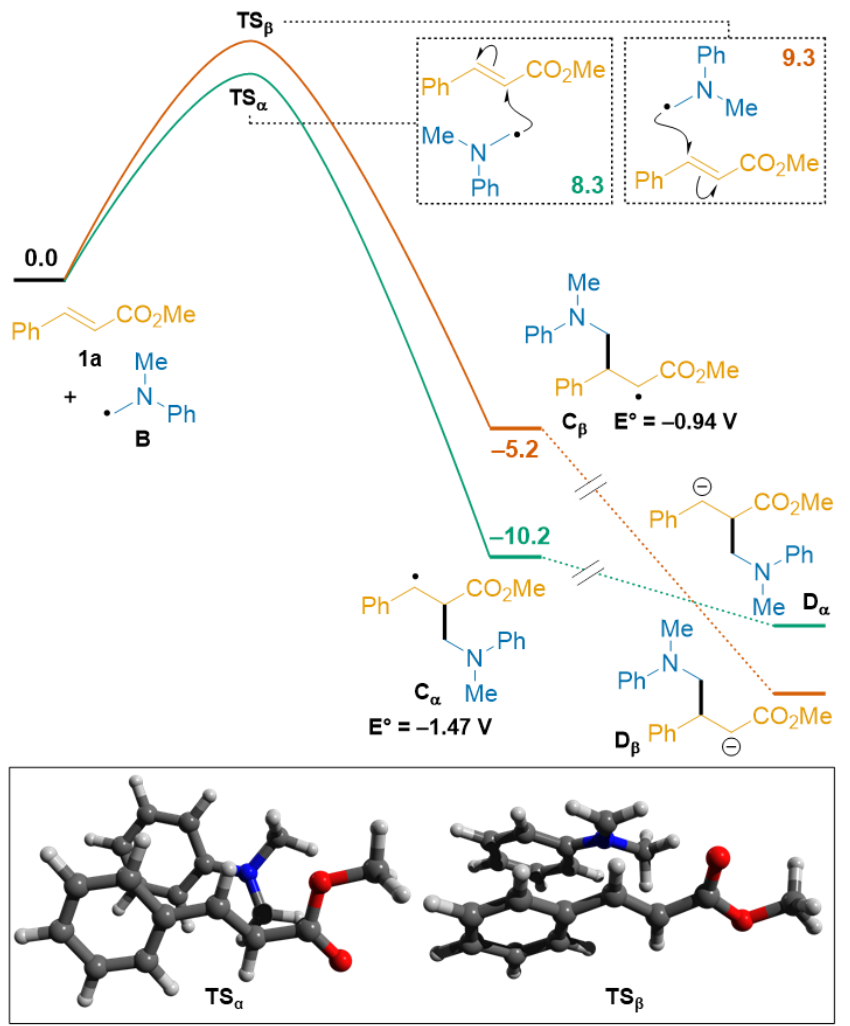

\section{AUTHOR INFORMATION}

\section{Corresponding Author}

*x.cambeiro@gre.ac.uk

\section{Author Contributions}

The manuscript was written through contributions of all authors.

\section{ACKNOWLEDGMENT}

We acknowledge Queen Mary University of London for partially funding this research. NAL thanks the European Commission for an MSCA fellowship (Project LIONCAT, 799664). JMO thanks QMUL for a PhD scholarship. 


\section{REFERENCES}

1. (a) Nesvadba, P. Radical Polymerization in Industry. In Encyclopedia of Radicals in Chemistry, Biology and Materials; Chatgilialoglu, C., Studer, A., Eds.; John Wiley and Sons, Inc., 2012; (b) Su, W.-F. Radical Chain Polymerization. In Principles of Polymer Design and Synthesis. Lecture Notes in Chemistry; Springer, Berlin, Heidelberg, 2013; Vol. 82, pp 137-183; (c) Chen, M.; Zhong, M.; Johnson, J. A. Light-Controlled Radical Polymerization: Mechanisms, Methods, and Applications. Chem. Rev. 2016, 116 (17), 10167-10211.

2. (a) Hart, D. J. Free-Radical Carbon-Carbon Bond Formation in Organic Synthesis. Science 1984, 223 (4639), 883-887; (b) Iqbal, J.; Bhatia, B.; Nayyar, N. K. Transition Metal-Promoted Free-Radical Reactions in Organic Synthesis: The Formation of Carbon-Carbon Bonds. Chem. Rev. 1994, 94 (2), 519-564; (c) Yao, H.; Hu, W.; Zhang, W. Difunctionalization of Alkenes and Alkynes via Intermolecular Radical and Nucleophilic Additions. Molecules 2021, 26 (1), 105.

3. (a) Giese, B., Formation of CC Bonds by Addition of Free Radicals to Alkenes. Angew. Chem. Int. Ed. Engl. 1983, 22 (10), 753764; (b) Srikanth, G. S. C.; Castle, S. L., Advances in radical conjugate additions. Tetrahedron 2005, 61 (44), 10377-10441.

4. (a) Lewis, F. D.; Ho, T.-I., Selectivity of tertiary amine oxidations. J. Am. Chem. Soc. 1980, 102 (5), 1751-1752; (b) Hu, J.; Wang, J.; Nguyen, T. H.; Zheng, N., The chemistry of amine radical cations produced by visible light photoredox catalysis. Beilstein J. Org. Chem. 2013, 9, 1977-2001; (c) Nakajima, K.; Miyake, Y.; Nishibayashi, Y., Synthetic Utilization of $\alpha$-Aminoalkyl Radicals and Related Species in Visible Light Photoredox Catalysis. Acc. Chem. Res. 2016, 49 (9), 1946-1956.

5. (a) Renaud, P.; Giraud, L., 1-Amino- and 1-Amidoalkyl Radicals: Generation and Stereoselective Reactions. Synthesis 1996, 1996 (08), 913-926; (b) Schmittel, M.; Burghart, A., Understanding Reactivity Patterns of Radical Cations. Angew. Chem. Int. Ed. Engl. 1997, 36 (23), 2550-2589.

6. (a) Das, S.; Kumar, J. S. D.; Thomas, K. G.; Shivaramayya, K.; George, M. V., Photocatalyzed multiple additions of amines to $\alpha-$ ,$\beta$-unsaturated esters and nitriles. J. Org. Chem. 1994, 59 (3), 628-634; (b) Harakat, D.; Pesch, J.; Marinković, S.; Hoffmann, N., Thiocarbonyl compounds as regulating reagent in the radical addition of tertiary amines with alkenes using photoelectron transfer conditions. Org. Biomol. Chem. 2006, 4 (7), 1202-1205; (c) Beatty, J. W.; Stephenson, C. R. J., Amine Functionalization via Oxidative Photoredox Catalysis: Methodology Development and Complex Molecule Synthesis. Acc. Chem. Res. 2015, 48 (5), 1474-1484.

7. For selected general reviews on photocatalysis, see: (a) Romero, N. A.; Nicewicz, D. A., Organic Photoredox Catalysis. Chem. Rev. 2016, 116 (17), 10075-10166; (b) Shaw, M. H.; Twilton, J.; MacMillan, D. W. C., Photoredox Catalysis in Organic Chemistry. J. Org. Chem. 2016, 81 (16), 6898-6926; (c) Marzo, L.; Pagire, S. K.; Reiser, O.; König, B., Visible-Light Photocatalysis: Does It Make a Difference in Organic Synthesis? Angew. Chem. Int. Ed. 2018, 57 (32), 1003410072; (d) Abderrazak, Y., Photocatalysis: A step closer to the perfect synthesis. J. Organomet. Chem. 2020, 920, 121335.

8. Ju, X.; Li, D.; Li, W.; Yu, W.; Bian, F., The Reaction of Tertiary Anilines with Maleimides under Visible Light Redox Catalysis. Adv. Synth. Catal. 2012, 354 (18), 3561-3567.

9. (a) Miyake, Y.; Nakajima, K.; Nishibayashi, Y., VisibleLight-Mediated Utilization of $\alpha$-Aminoalkyl Radicals: Addition to Electron-Deficient Alkenes Using Photoredox Catalysts. J. Am. Chem. Soc. 2012, 134 (7), 3338-3341; (b) Zhu, S.; Das, A.; Bui, L.; Zhou, H.; Curran, D. P.; Rueping, M., Oxygen Switch in Visible-Light Photoredox Catalysis: Radical Additions and Cyclizations and Unexpected CC-Bond Cleavage Reactions. J. Am. Chem. Soc. 2013, 135 (5), 18231829.

10. (a) Kohls, P.; Jadhav, D.; Pandey, G.; Reiser, O., Visible Light Photoredox Catalysis: Generation and Addition of N-Aryltetrahydroisoquinoline-Derived $\alpha$-Amino Radicals to Michael Acceptors. Org. Lett. 2012, 14 (3), 672-675; (b) Ruiz Espelt, L.; Wiensch, E. M.; Yoon, T. P., Brønsted Acid Cocatalysts in Photocatalytic Radical Addition of $\alpha$-Amino $\mathrm{C}-\mathrm{H}$ Bonds across Michael Acceptors. J. Org. Chem. 2013, 78 (8), 4107-4114; (c) Murphy, J. J.; Bastida, D.; Paria,
S.; Fagnoni, M.; Melchiorre, P., Asymmetric catalytic formation of quaternary carbons by iminium ion trapping of radicals. Nature $\mathbf{2 0 1 6}$, 532 (7598), 218-222; (d) Lin, S.-X.; Sun, G.-J.; Kang, Q., A visiblelight-activated rhodium complex in enantioselective conjugate addition of $\alpha$-amino radicals with Michael acceptors. Chem. Commun. 2017, 53 (54), 7665-7668; (e) McManus, J. B.; Onuska, N. P. R.; Nicewicz, D. A., Generation and Alkylation of alpha-Carbamyl Radicals via Organic Photoredox Catalysis. J. Am. Chem. Soc. 2018, 140 (29), 9056-9060.

11. Aycock, R. A.; Pratt, C. J.; Jui, N. T., Aminoalkyl Radicals as Powerful Intermediates for the Synthesis of Unnatural Amino Acids and Peptides. ACS Catal. 2018, 8 (10), 9115-9119.

12. (a) Dai, X.; Cheng, D.; Guan, B.; Mao, W.; Xu, X.; Li, X., The Coupling of Tertiary Amines with Acrylate Derivatives via Visible-Light Photoredox Catalysis. J. Org. Chem. 2014, 79 (15), 7212 7219; (b) Dai, X.; Mao, R.; Guan, B.; Xu, X.; Li, X., Visible light photoredox catalysis: regioselective radical addition of aminoalkyl radicals to 2,3-allenoates. RSC Adv. 2015, 5 (68), 55290-55294.

13. Hepburn, H. B.; Melchiorre, P., Brønsted acid-catalysed conjugate addition of photochemically generated $\alpha$-amino radicals to alkenylpyridines. Chem. Commun. 2016, 52 (17), 3520-3523.

14. For a general review, see: Kanegusuku, A. L. G.; Roizen, J. L., Recent Advances in Photoredox-Mediated Radical Conjugate Addition Reactions: An Expanding Toolkit for the Giese Reaction. Angew. Chem. Int. Ed. 2021. https://doi.org/10.1002/anie.202016666.

15. (a) Miyake, Y.; Ashida, Y.; Nakajima, K.; Nishibayashi, Y., Visible-light-mediated addition of $\alpha$-aminoalkyl radicals generated from $\alpha$-silylamines to $\alpha, \beta$-unsaturated carbonyl compounds. Chem. Commun. 2012, 48 (55), 6966-6968; (b) Nakajima, K.; Kitagawa, M.; Ashida, Y.; Miyake, Y.; Nishibayashi, Y., Synthesis of nitrogen heterocycles via $\alpha$-aminoalkyl radicals generated from $\alpha$-silyl secondary amines under visible light irradiation. Chem. Commun. 2014, 50 (64), 8900-8903; (c) Ruiz Espelt, L.; McPherson, I. S.; Wiensch, E. M.; Yoon, T. P., Enantioselective Conjugate Additions of $\alpha$-Amino Radicals via Cooperative Photoredox and Lewis Acid Catalysis. J. Am. Chem. Soc. 2015, 137 (7), 2452-2455; (d) Cao, Z.-Y.; Ghosh, T.; Melchiorre, P., Enantioselective radical conjugate additions driven by a photoactive intramolecular iminium-ion-based EDA complex. Nature Commun. 2018, 9 (1), 3274; (e) Shen, X.; Li, Y.; Wen, Z.; Cao, S.; Hou, X.; Gong, L., A chiral nickel DBFOX complex as a bifunctional catalyst for visible-light-promoted asymmetric photoredox reactions. Chem. Sci. 2018, 9 (20), 4562-4568; (f) Le Saux, E.; Ma, D.; Bonilla, P.; Holden, C. M.; Lustosa, D.; Melchiorre, P., A General Organocatalytic System for Enantioselective Radical Conjugate Additions to Enals. Angew. Chem. Int. Ed. 2021, 60 (10), 5357-5362.

16. (a) Chu, L.; Ohta, C.; Zuo, Z.; MacMillan, D. W. C., Carboxylic Acids as A Traceless Activation Group for Conjugate Additions: A Three-Step Synthesis of ( \pm )-Pregabalin. J. Am. Chem. Soc. 2014, 136 (31), 10886-10889; (b) Millet, A.; Lefebvre, Q.; Rueping, M., Visible-Light Photoredox-Catalyzed Giese Reaction: Decarboxylative Addition of Amino Acid Derived $\alpha$-Amino Radicals to ElectronDeficient Olefins. Chem. Eur. J. 2016, 22 (38), 13464-13468; (c) McCarver, S. J.; Qiao, J. X.; Carpenter, J.; Borzilleri, R. M.; Poss, M. A.; Eastgate, M. D.; Miller, M. M.; MacMillan, D. W. C., Decarboxylative Peptide Macrocyclization through Photoredox Catalysis. Angew. Chem. Int. Ed. 2017, 56 (3), 728-732.

17. (a) Miyazawa, K.; Koike, T.; Akita, M., Hydroaminomethylation of Olefins with Aminomethyltrifluoroborate by Photoredox Catalysis. Adv. Synth. Catal. 2014, 356 (13), 2749-2755; (b) Ma, J.; Lin, J.; Zhao, L.; Harms, K.; Marsch, M.; Xie, X.; Meggers, E., Synthesis of $\beta$-Substituted $\gamma$-Aminobutyric Acid Derivatives through Enantioselective Photoredox Catalysis. Angew. Chem. Int. Ed. 2018, 57 (35), 11193-11197.

18. Lovett, G. H.; Sparling, B. A., Decarboxylative Anti-Michael Addition to Olefins Mediated by Photoredox Catalysis. Org. Lett. 2016, 18 (14), 3494-3497.

19. Some examples of $\alpha$-selective addition of radicals other than $\alpha$-aminoalkyl have been reported: (a) Ando, Y.; Kamatsuka, T.; Shinokubo, H.; Miyake, Y., Selective $\alpha$-arylation of $\alpha, \beta$-unsaturated imides mediated by a visible light photoredox catalyst. Chem. Commun. 2017, 53 (65), 9136-9138; (b) Gu, F.; Huang, W.; Liu, X.; Chen, W.; Cheng, X., Substituted Hantzsch Esters as Versatile Radical Reservoirs 
in Photoredox Reactions. Adv. Synth. Catal. 2018, 360 (5), 925-931; (c) Huang, Y.-S.; Wang, J.; Zheng, W.-X.; Zhang, F.-L.; Yu, Y.-J.; Zheng, M.; Zhou, X.; Wang, Y.-F., Regioselective radical hydroboration of electron-deficient alkenes: synthesis of $\alpha$-boryl functionalized molecules. Chem. Commun. 2019, 55 (79), 11904-11907; (d) Ren, S.C.; Zhang, F.-L.; Xu, A.-Q.; Yang, Y.; Zheng, M.; Zhou, X.; Fu, Y.; Wang, Y.-F., Regioselective radical $\alpha$-borylation of $\alpha, \beta$-unsaturated carbonyl compounds for direct synthesis of $\alpha$-borylcarbonyl molecules. Nature Commun. 2019, 10 (1), 1934; (e) Zhao, Q.; Jin, J.-K.; Wang, J.; Zhang, F.-L.; Wang, Y.-F., Radical $\alpha$-addition involved electrooxidative $[3+2]$ annulation of phenols and electron-deficient alkenes. Chem. Sci. 2020, 11 (15), 3909-3913.

20. (a) Steer, D.; Lew, R.; Perlmutter, P.; Smith, A.; Aguilar, M.-I. $\beta$-Amino Acids: Versatile Peptidomimetics. Curr. Med. Chem. 2002, 9 (8), 811-822; (b) von Nussbaum, F.; Spiteller, P. $\beta$-Amino Acids in Nature. In Highlights in Bioorganic Chemistry: Methods and Applications; Schmuck, C., Wennemers, H., Eds.; Wiley-VCH, Weinheim, 2004; pp 63-89.

21. For reviews on $\beta$-amino acid synthesis, see: (a) Lelais, G.; Seebach, D. $\beta^{2}$-Amino Acids-Syntheses, Occurrence in Natural Products, and Components of $\beta$-Peptides ${ }^{1,2}$. Biopolymers 2004, 76 (3), 206243; (b) Enantioselective Synthesis of $\beta$-Amino Acids; 2nd ed., Juaristi, E., Soloshonok, V. A., Eds.; John Wiley \& Sons, Inc.: Hoboken, 2005. (c) Weiner, B.; Szymański, W.; Janssen, D. B.; Minnaard, A. J.; Feringa, B. L., Recent advances in the catalytic asymmetric synthesis of $\beta$-amino acids. Chem. Soc. Rev. 2010, 39 (5), 1656-1691; (d) Noda, H.; Shibasaki, M., Recent Advances in the Catalytic Asymmetric Synthesis of $\beta^{2}$ - and $\beta^{2,2}$-Amino Acids. Eur. J. Org. Chem. 2020, 2020 (16), $2350-2361$

22. (a) Zhao, G.; Yang, C.; Guo, L.; Sun, H.; Chen, C.; Xia, W., Visible light-induced oxidative coupling reaction: easy access to Mannich-type products. Chem. Commun. 2012, 48 (17), 2337-2339; (b) Freeman, D. B.; Furst, L.; Condie, A. G.; Stephenson, C. R. J. Functionally Diverse Nucleophilic Trapping of Iminium Intermediates Generated Utilizing Visible Light. Org. Lett. 2012, 14 (1), 94-97.

23. Rueping, M.; Vila, C.; Koenigs, R. M.; Poscharny, K.; Fabry, D. C., Dual catalysis: combining photoredox and Lewis base catalysis for direct Mannich reactions. Chem. Commun. 2011, 47 (8), 2360-2362.

24. Wei, G.; Zhang, C.; Bureš, F.; Ye, X.; Tan, C.-H.; Jiang, Z., Enantioselective Aerobic Oxidative C(sp3)-H Olefination of Amines via Cooperative Photoredox and Asymmetric Catalysis. ACS Catal. 2016, 6 (6), 3708-3712.

25. (a) Koike and Akita reported 5\% yield in the hydroaminoalkylation of styrene with an aminomethyltrifluoroborate compound, see ref. 17a; (b) Sparling reported four examples with $N$-Boc-pyrrolidin-2yl radical generated by decarboxylation of $N$-Boc-proline, see ref. 18; (c) A related alkene difunctionalisation has been reported recently, see: Zhang, B.; Yi, Y.; Wu, Z.-Q.; Chen, C.; Xi, C., Photoredox-catalyzed dicarbofunctionalization of styrenes with amines and $\mathrm{CO}_{2}$ : a convenient access to $\gamma$-amino acids. Green Chem. 2020, 22 (18), 5961-5965.
26. Recently, transition metal-catalysed hydroaminoalkylation of simple alkenes has been reported, see for example: (a) Herzon, S. B.; Hartwig, J. F., Direct, Catalytic Hydroaminoalkylation of Unactivated Olefins with N-Alkyl Arylamines. J. Am. Chem. Soc. 2007, 129 (21), 6690-6691; (b) DiPucchio, R. C.; Roşca, S.-C.; Schafer, L. L., Catalytic and Atom-Economic $\mathrm{C}-\mathrm{C}$ Bond Formation: Alkyl Tantalum Ureates for Hydroaminoalkylation. Angew. Chem. Int. Ed. 2018, 57 (13), 34693472; (c) Edwards, P. M.; Schafer, L. L., Early transition metal-catalyzed $\mathrm{C}-\mathrm{H}$ alkylation: hydroaminoalkylation for Csp3-Csp3 bond formation in the synthesis of selectively substituted amines. Chem. Commun. 2018, 54 (89), 12543-12560; (d) Bielefeld, J.; Doye, S., Fast Titanium-Catalyzed Hydroaminomethylation of Alkenes and the Formal Conversion of Methylamine. Angew. Chem. Int. Ed. Engl. 2020, 59 (15), 6138-6143; (e) For an acid-catalysed hydroaminomethylation using formaldehyde aminals as starting material, see: Kaiser, D.; Tona, V.; Goncalves, C. R.; Shaaban, S.; Oppedisano, A.; Maulide, N., A General Acid-Mediated Hydroaminomethylation of Unactivated Alkenes and Alkynes. Angew. Chem. Int. Ed. Engl. 2019, 58 (41), 1463914643; For a review on catalytic amine synthesis, see: (f) Trowbridge, A.; Walton, S. M.; Gaunt, M. J., New Strategies for the TransitionMetal Catalyzed Synthesis of Aliphatic Amines. Chem. Rev. 2020, 120 (5), 2613-2692.

27. Larionova, N. A.; Miyatake Ondozabal, J.; Cambeiro, X. C., Reduction of Electron-Deficient Alkenes Enabled by a Photoinduced Hydrogen Atom Transfer. Adv. Synth. Catal. 2021, 363 (2), 558-564.

28. See ESI for details.

29. Newcomb, M. Radical Kinetics and Clocks. In Encyclopedia of Radicals in Chemistry, Biology and Materials; Chatgilialoglu, C., Studer, A., Eds.; John Wiley \& Sons, Ltd, 2012.

30. The only detected by-products were double alkylation of the amine with two units of the alkene, and a dehydrogenated derivative of product 5 .

31. This process is well-precedented, see for example: Prier, C. K.; MacMillan, D. W. C. Amine $\alpha$-Heteroarylation via Photoredox Catalysis: A Homolytic Aromatic Substitution Pathway. Chem. Sci. 2014, 5 (11), 4173-4178.

32. (a) Wu, Y.; Kim, D.; Teets, T. S., Photophysical Properties and Redox Potentials of Photosensitizers for Organic Photoredox Transformations. Synlett 2021. https://doi.org/10.1055/a-1390-9065. (b) Fukuzumi, S.; Yuasa, J.; Satoh, N.; Suenobu, T. Scandium Ion-Promoted Photoinduced Electron Transfer from Electron Donors to Acridine and Pyrene. Essential Role of Scandium Ion in Photocatalytic Oxygenation of Hexamethylbenzene. J. Am. Chem. Soc. 2004, 126 (24), $7585-7594$.

33. Condie, A. G.; González-Gómez, J. C.; Stephenson, C. R. J., Visible-Light Photoredox Catalysis: Aza-Henry Reactions via $\mathrm{C}-\mathrm{H}$ Functionalization. J. Am. Chem. Soc. 2010, 132 (5), 1464-1465. 